\title{
Use of Information and Communication Technology ICT in Agriculture to Uplift Small Scale Farmers in Rural Pakistan
}

\author{
Sabir Hussain Awan ${ }^{1}$, Sheeraz Ahmed ${ }^{2}$, Muhammad Zaheer Hashim ${ }^{3}$ \\ ${ }^{1}$ Department of Electrical Engineering, Iqra National University, Peshawar, Pakistan \\ ${ }^{2}$ Department of Computer Science, Iqra National University, Peshawar, Pakistan \\ ${ }^{3}$ School of Economics and Management, Beijing University of Technology, Beijing, China
}

Email address:

sabirawanptcl@gmail.com (S.H. Awan), sheerazahmed901@gmail.com (S. Ahmed), zaheerhashim1986@gmail.com (M. Z. Hashim)

${ }^{*}$ Corresponding author

To cite this article:

Sabir Hussain Awan, Sheeraz Ahmed, Muhammad Zaheer Hashim. Use of Information and Communication Technology ICT in Agriculture to Uplift Small Scale Farmers in Rural Pakistan. American Journal of Engineering and Technology Management.

Vol. 4, No. 1, 2019, pp. 25-33. doi: 10.11648/j.ajetm.20190401.14

Received: February 3, 2019; Accepted: March 11, 2019; Published: April 22, 2019

\begin{abstract}
The research was conducted to determine the agricultural information needs of the rural farmers and to provide a solution to access this information in the province of Khyber Pakhtunkhwa (KPK) Pakistan. The research was conducted in Ten (10) Villages of different districts of KPK and a number of 460 respondents were selected for study, the study was conducted through a survey method, Face to Face interviews, focus group discussion and farmer meetings, data was collected and analyzed through descriptive statistics, percentage, frequency tables. The results indicated that most of the respondents $(34.78 \%)$ fall in age group between $41-50$ years, it is also found that the first preferred source of information of the farmers is fellow farmers (37.39\%) following by Radio (29.13\%), Major barriers to access modern information systems is high illiteracy (39.43\%) and non-availability of local information centers (36.08\%). During the study, a large of the number of farmers acknowledged that they are not familiar with modern practices of agriculture because they are not facilitated with new technologies to access agricultural information; as a result, they are not using such techniques and relying on traditional ways. The research study also identified that due to the highly localized nature of information and several barriers this is very essential to equip rural farmers with updated information through use of (ICT) to enhance production and improve their livelihood.
\end{abstract}

Keywords: GDP, ICT, Framework, Production, Livelihood

\section{Introduction}

Pakistan government has taken many steps to improve farming by introducing innovative scientific research methods to improve production and livelihood. The agriculture sector is linked with other sectors of the economy and playing a remarkable role in enhancing country socioeconomic development. Share of Agriculture in GDP is $19.8 \%$ and labor employment share is $42.3 \%$ this sector recorded negative growth of $-0.19 \%$ against the last year growth the decline in growth is due to the drop in production of cotton, maize, rice and other due to extreme weather condition and lack of timely and accurate information [1]. Similar to numerous developing countries agriculture is seen as the vehicle for development also in Pakistan but due to the unavailability of suitable information and awareness system, its role is less effective [2]. The core causes the restrictive farmer to raise income and production is the lack of appropriate information sources and systems in a rural area proper transfer of agriculture information in rural area can fill the information gap to improve production and farmer's income, the government requires well-organized system to facilitate the farmer needs [3]. Well-timed transfer of agriculture information is the most vital part of the farming system and important promoter for agriculture development helping for a revolution of the rural farmers [4].

Presently electronic media is being used as the main source for transfer of agriculture information but not valuable due to time constraint [5]. In rural areas farmers are getting 
information from neighbors, friends, relative farmers and dealers of companies to meet the desired needs [6]. Print media is also being used for agriculture information [7]. Various sources of communication like magazines, newspapers, books, and pamphlets are being used for information purpose [8]. The extension field staff is also providing information to farmers but their role is not impressive and their communication with farmers is miserable, extension field staff should visit farmers to train and support them for the solution of their problems related to agriculture practices [9]. Smallholder farmers are facing difficulties to enter the market due to the lack of relevant and updated information [10]. They need a different kind of information to plant their crops shown as figure 1. [11]

Like access to market: Farmers always need proper information about wholesale output and input, market trends and alerts to sell out their products because in developing countries middlemen often purchase products from farmers at a much lower cost as compare to real market rates due to which farmers get low profit or some time bear losses. Likewise, input prices such as seeds, fertilizers, pesticides, and farm machinery can help to use these inputs in updated ways to reduce costs and enhance profitability. Weather forecast: Farmers cannot make a proper decision throughout the crop management cycle without real-time weather information, therefore, farmers always need timely and appropriate weather forecast for preparation of land planting of crops and making the decision to irrigate or fertilize crops and harvesting/post harvesting decisions. Crop Selection: Farmers also need information about the most demanded and profitable crops because due to unawareness some time farmers select less value crop due to which they cannot find buyers to sell their crops and unfortunately again they bear losses [12].

Modern technologies have opened many ways and opportunities to get appropriate weather forecast and market information to make good decision but in developing countries information dissemination systems are weak and farmers are limited to traditional ways like fellow farmers, TV, Radio and electronic media which cannot fulfill their desired requirement, therefore, farmers need an easily accessible and low-cost information system and support to improve their productivity and probability [13]. With the passage of time paradigm of the agriculture is changing, because due to advancement in technology decision-making techniques have been changed and through use of latest technology timely and accurate been made and farmers efficiency has improved [14]. Smart farming through the use of ICT is being promoted nationally and internationally to encourage farmers community [15]. The use of ICT is not only significant to improve extension services, but also to scientists who can use ICTs that facilitate connections between them, experts and farmers. Farmers are rich sources to provide useful data on their activities and experiences. ICT-based approaches are cost-effective for information collection and delivery to make in time decisions to perform farm-related activities to improve productivity and income
[16].

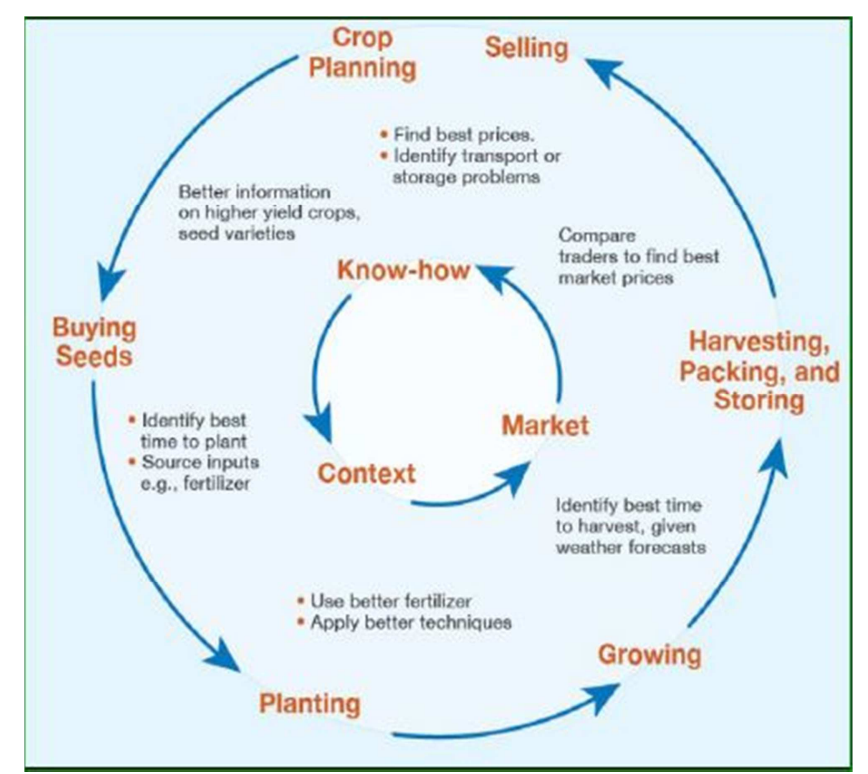

Figure 1. Information needed by farmers.

\section{Literature Review}

Pakistan is basically an agricultural country and agriculture is one of the most important sectors of its economy its contribution is about $19.8 \%$ of the gross domestic product (GDP) and $42.5 \%$ of rural people are associated with agriculture. Khyber Pakhtunkhwa (KPK) $75 \%$ population depends on Agriculture, Maize 18\%, Sugarcane $13 \%$, Tobacco $9 \%$ and Wheat $22 \%$ account for agricultural production value and the remaining $30 \%$ is livestock. The majority of the farmers in KPK are small landholders as $60 \%$ of landholders have less than 2.5 acres [1]. Although agriculture is playing a remarkable role in the economy its production is still below potential and much lower than many other countries of the world Actual yield is much below its real potential [13]. This is a clear indication that farmers are still relying on traditional farming techniques and modern day technologies are not being utilized in agriculture [14].

The need of the time is to make use of Information and Communication Technology (ICT) in the field of Agriculture to meet the desired results. In this situation, farmers need appropriate information access to modern day technologies [15]. Existing agricultural information delivery system in Pakistan is not properly playing its role to facilitate rural farmers with the latest information [16]. In this scenario (ICT) can play a significant role to provide the latest information to rural farmers particularly in developing countries [17]. ICT can fill the communication gap between farmers and agricultural information providers with a wellorganized and cost-effective way [18, 19]. Farmers can get help to access the market to obtain better prices for their products and can earn more profit by avoiding middlemen interference [20, 21]). In ICT era cellular services are playing a remarkable role to connect people and these services can 
also play an effective role to transfer agricultural information to the rural community directly to improve their farming output and make easy access to the market as well [22, 23].

The agricultural information system in Pakistan is facing many barriers and one the main barrier is less of use of ICT for transfer of agricultural information, high illiteracy, low income, lack of training and weak collaboration among stakeholders are also creating problems in transfer of agricultural information [26]. In Kenya, a study was conducted which showed that ICT-based market information system (MIS) project had a positive and significant effect on the usage of purchased seed, fertilizer, labor productivity, and land productivity [27]

Over the last three decades, China agriculture sector has been transformed from traditional to modern practices through the effective deployment of Information and Communication Technologies and still working to introduce new ICT models to help farmers [28]. The Situation of Pakistan is a slightly different small -scale majority farmers are illiterate and unaware about the latest development in the field of agriculture and the necessary support system is not provided to them despite they are willing to adopt new systems to improve their farming, ICT has the capacity to be used in many ways in agriculture however many ICT efforts are ineffective the question then is how can the impact of ICT in agriculture be improved, ICTs Knowledge can contribute to better considerate, how these farmers can be supported to improve their efficiency and thus their profitability, leading to more sustainable farms [29]. The author has tried to address this issue through the use of Web portal and mobile SMS model but it has its own limitation because data needs to be collected through surfing of different websites that need proper knowledge of dedicated websites [30]. There is a need to start regular ICT programs to transfer timely information to farmers and should also establish an Information Hub Center (IHC) at the tehsil level to facilitate farmers [31].

\section{Research Significance}

Keeping in view the economic globalization and rapid climate change farmers need specific and low-cost information systems because only well-aware farmers can select a suitable variety of seeds, fertilizers, pesticides, and other important agriculture inputs. For land preparation, selection of crops, selection of Seeds, irrigation, Crop growth, Fertilizing, Harvesting farmers need proper knowledge to perform these activities. Farmers also need to know updated weather and market forecasting. The local and global agriculture market is rapidly changing and it is difficult for small -scale farmers to maintain their competitiveness without using advanced technology. The need of the time is to develop optimal information sharing system as presently available information systems are adequate, Farmers should not overload with a lot of information but summarized, relevant, clear and updated information should be provided to them so that it could satisfy their basic needs. A new appropriate system that could satisfy multidisciplinary agriculture knowledge into an easily understandable cost-effective information system effortlessly available to small-scale farmers. We have learned from many studies that developing countries are utilizing ICT for multiple purposes and getting benefits from these technologies, the countries that failed to properly use this resource are left behind in international development competition.

\section{Research Contribution}

In this research, we made an effort to present a solution to bridge the communication gap between farmers and agriculture advisers through Information and communication technology (ICT). This work determined the need for ICT services in farming and identified the basic requirements of small scale farmer communities to produce an efficient crop. A smart framework is developed to collect the desired information and deliver it to the concerned community such that both literate and illiterate farmers utilize it to improve their farming techniques.

\section{Smart Framework Description}

Our framework is well-versed by finding of research study and suitable to existing telecom setup in Pakistan. A smart framework is developed in such a way that can easily collect the desired information and deliver it to the concerned community such that both literate and illiterate farmers utilize it to improve their farming techniques.

Objectives of Smart framework were

1. Transfer of timely and accurate information to farmers about plant health, weather updates, market prices, crop rotation, and crop diseases, climate change and new technologies. The information will be gathered through use of web and transfer to farmers by their cell phones.

2. In Pakistan literacy level is low therefore the information will be assembled and transfer in local language.

3. Framework will also be capable to transfer voice based information so that illiterate famers can also get benefit equally.

4. Agriculture field assistant service will also be available to tackle complex problem and support famers during field activities.

5. Automatic updates will also be shared with farmers time to time.

For web portal we proposed Java enterprise edition (J2EE) which is used for heavy programs and have many users and for data base we proposed MySQL which open source data base and widely being used for web development. 


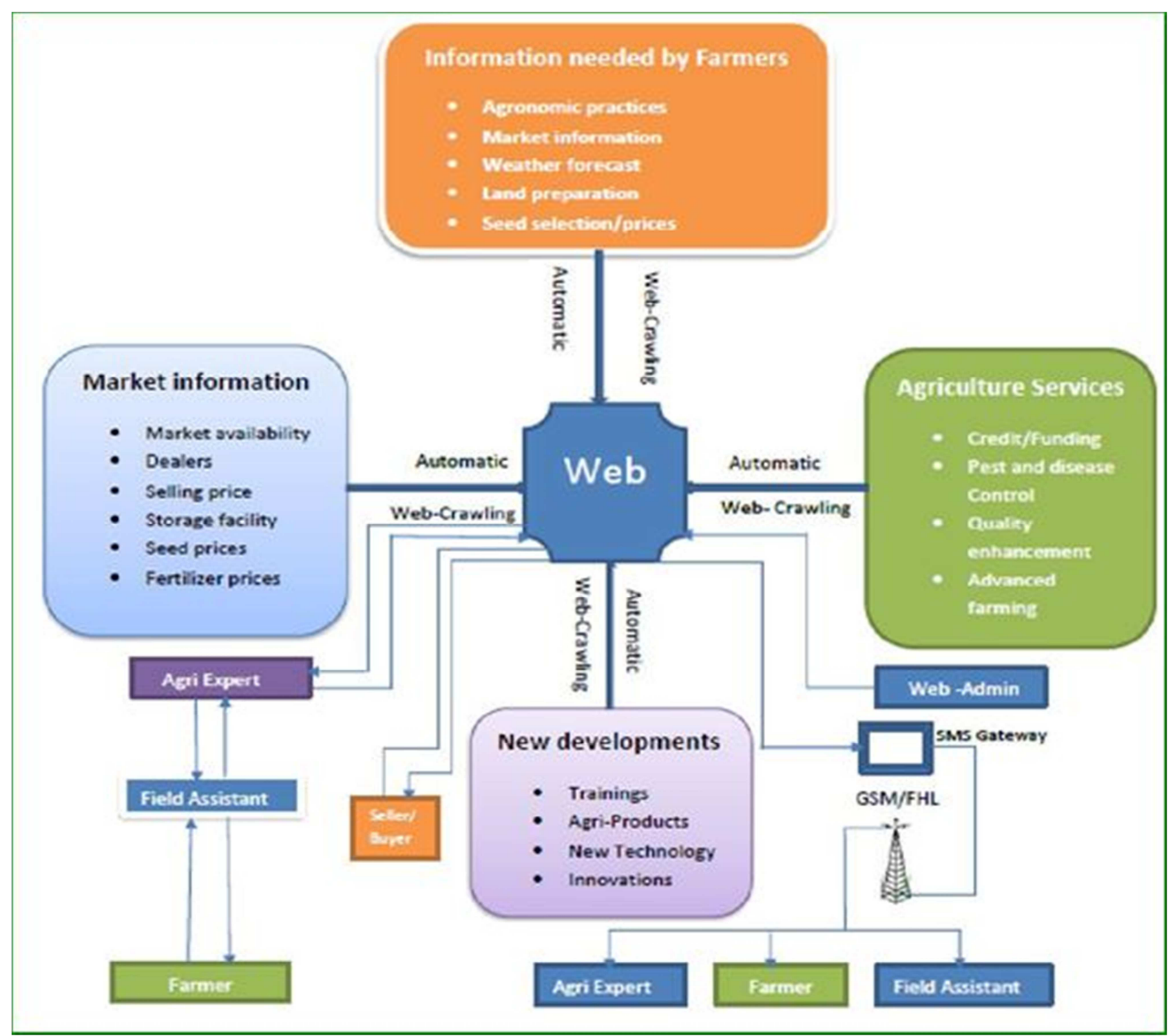

Figure 2. Smart framework for transfer of agricultural information to farmers.

Following will be the users of web

1. Admin

2. Agro-Expert

3. Farmer

4. Field Assistant

5. Buyer/Seller

Admin: Admin is vital user of web portal he will manage overall system the user interface will be developed in admin panel in the prime faces.

Following function will be performed by Admin at the web portal.

Sending of SMS: Admin will send SMS to farmers on localized bases like District, local language. SMS is automatically generated when administrator select the options. Administrator has the options to send SMS in English or Urdu.

Automatic SMS broad casting: Admin will setup time for broad casting of SMS and desired location from the list already mentioned in the web portal SMS will be delivered to all selected farmers and other stakeholders'. For the function Prime Faces Poll component is proposed.

Automated web crawling: Admin will capable to run web crawler to collect information from different websites through open source web crawler (Crawler 4J). Desired information will be fetched and then store in data base. For this purpose JSoup parser is used for parsing of HTML page which is an open source parser.

User Management: In Admin module user management is much important function, Admin can access and view all the users of the portal and can add or delete user.

Agro-Expert: In Pakistan Agricultural experts extend support to farmers in yielding activities but they do not have proper mechanism to share their knowledge with farmers. We have expert advisor module in our portal so that agro-expert can easily provide knowledge and support to farmer.

Farmer: Farmer is most important user and focal point in the portal the whole system is framed to share information with the famers to produce efficient crop and improve their 
livelihood.

Field Assistant: Field assistant are representatives of agriculture department which will provide support to farmers when the face complex issues during farming activities.

Sellers and Buyers Module: In our framework there is seller and buyers' module through which seller and buyers will register to sell seed and fertilizers and to buy crops.

Language Translation Module: In Pakistan majority of the farmers are illiterate or less educated and cannot understand English so we used language translating module Google translation API2.0 which is commercially being used to translate language. In Pakistan Urdu is common understanding language therefore English to Urdu translation will be used to deliver SMS.

SMS Gateway: We used Kannel as SMS gateway server. Kannel will be installed on the Linux Ubuntu 12.04 for configuration and send SMS to farmers and other stakeholders.

\section{Research Methodology}

In this study cross-sectional descriptive design was applied to discover numerous problems faced by the farmers in the transfer of agricultural information. This design is costeffective and permits a combination of different survey methods for the collection of both quantitative and qualitative data and suggests rapid results with nominal costs. This type of survey also permits relationship creation with the respondent. For more in-depth information personnel interaction with farmers was also made. Detailed interviews and meeting with farmers were conducted to get visual clues for those behaviors which were observed director when the farmer became unwilling to discuss.

\subsection{Area of Study}

The study was conducted in Khyber Pakhtunkhwa (KPK) Pakistan. KPK has seven (7) division and twenty-five (25) districts and Seventy one (71) Tehsils. [Pakistan Bureau Statistics 2017). On the basis of small-scale and poor farmers five (5) Districts Peshawar, Charsada, Mardan, Kohat, and Malakand were selected for study to find out the basic information needs of farmers to improve production.

\subsection{Population and Sampling Procedure}

The study targeted small-scale farmers in District Peshawar, Charsada, Mardan, Kohat, and Malakand. A sample size of 460 small-scale farmers was selected for the study. Ten (10) villages two from each district Tarnab, Nasir Pur from Peshawar, Rajjar, Utmanzai from Charsada, Toru, Katlang from Mardan, Kaghuzi, Tulbagh from Kohat and Sakhakot, Thana Khas from Malakand were selected through simple random technique. From a list of those farmers in each village, 46 of them were selected using a systematic sampling technique to obtain 460 respondents. In this technique, the researcher randomly selects a starting number which was referred to as the first subject. He then picks another integer (2) which serves as the constant difference between any two consecutive numbers in the progression. That means the sampling was done at an interval of 2, which is after two individuals the next is included in the sample. However, we used sample size of 460 because the few farmers were unable to be contacted.

To conduct survey and group discussion following steps were taken.

1. We identified one focal person from each village to facilitate during discussion process.

2. We selected farmers on the basis of their willingness.

3. Survey and group discussion were made at their convenient places

4. Questionnaire was developed in local language and later on converted into English

5. The body language and expression of the farmers were recorded during group discussion to gauge their acceptability to the concept of using ICT service.

\subsection{Data Collection}

The research study has relied on primary data collected from farmers, therefore, we used four sets of data collection Instruments these instruments were developed through a consultative process involving the research and a review and the instruments were designed in line with the research objectives. The first used instrument was a questionnaire sourced for quantitative data from selected respondents, second was Face to Face interviews, third was a focus group discussion and the fourth one was farmers meeting.

\subsection{Data Analysis}

The data were carefully organized and analyzed by using frequency and percentage tables and investigations were properly recorded.

Table 1. Farmers attributes.

\begin{tabular}{llll}
\hline Farmers attribute & Response (N=460) & \% \\
\hline \multirow{4}{*}{ Age } & Below 18 Years & 51 & 10.86 \\
& 18-30 Years & 99 & 21.52 \\
& 31-40 years & 114 & 24.78 \\
& 41-50 years & 160 & 34.78 \\
& 51-60 years & 26 & 5.65 \\
& 60 and above years & 10 & 2.17 \\
Gender & Total & 460 & 100 \\
& Male & 405 & 88.04 \\
& Female & 55 & 11.95 \\
& Total & 460 & 100 \\
& Illiterate & 120 & 26.08 \\
& Primary & 122 & 26.52 \\
Education & Middle & 109 & 23.69 \\
& Secondary & 81 & 17.60 \\
& Higher secondary & 25 & 5.43 \\
& Graduation & 3 & 0.65 \\
& Post-graduation & 0 & 0 \\
& Total & 460 & 100 \\
& Low & 251 & 54.56 \\
& Medium & 178 & 38.69 \\
& High & 31 & 6.73 \\
& Total & 460 & 100 \\
& Less than 10 years & 65 & 14.13 \\
\hline \multirow{5}{*}{ Income } & & &
\end{tabular}




\begin{tabular}{llll}
\hline Farmers attribute & Response $(\mathbf{N}=\mathbf{4 6 0})$ & $\mathbf{\%}$ \\
\hline Experience & $10-20$ & 270 & 58.69 \\
& $21-30$ & 90 & 19.56 \\
& $31-40$ & 35 & 7.60 \\
& Total & 460 & 100 \\
\hline
\end{tabular}

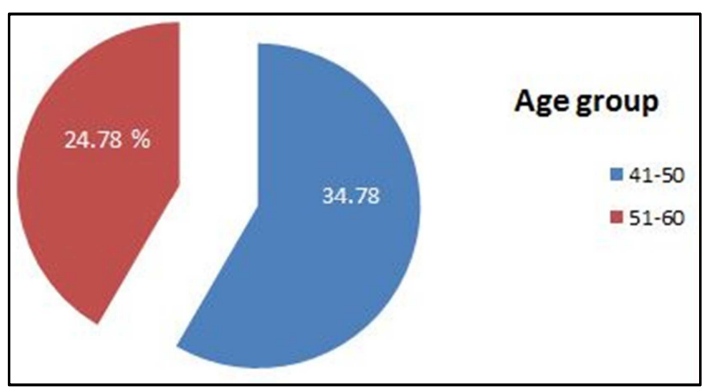

Figure 3. Farmers age group.

Farmer's attributes as shown in Table 1 and illustrated in figure 3 . The age group pertaining to the $41-50$ has highest percentage $160(34.78 \%)$ trailed by $31-40$ age group, 114 $(24.78 \%)$ age group of $51-60,26(5.65 \%)$ and above 60 years were $10(2.65 \%)$ While, Gender-wise distribution shows that Male has the highest percentage of $405(88.04 \%)$ and female have less percentage of $55(11.5 \%)$. Farmer's educational status tells us that the majority of the farmers are less educated $122(26.52 \%)$ followed by illiterate 120 (26.08\%). As so far as income level is concerned the majority of the farmers have low income $251(54.56 \%)$ followed by medium level income 178 (38.69\%), whereas maximum farmers have experience of 10-20 years 270 (58.69\%) followed by 21-30 years $90(19.56 \%)$.

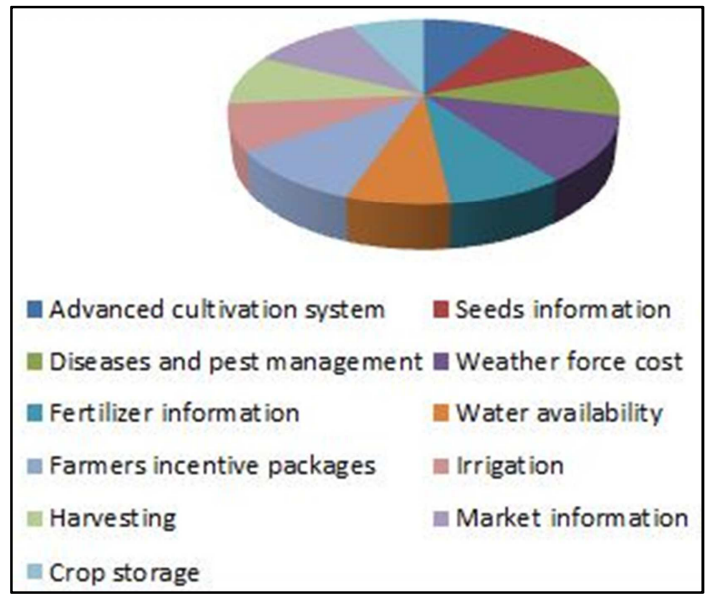

Figure 4. Type of information needed by farmers.

Table 2. Type of information needed by farmers.

\begin{tabular}{lllllll}
\hline Type of Information & Never & Rarely & Occasion & Often & Very Often & Total \\
\hline \multirow{2}{*}{ Advanced cultivation system } & 70 & 48 & 145 & 150 & 47 & 460 \\
& $15.21 \%$ & $10.43 \%$ & $31.52 \%$ & $32.60 \%$ & $10.21 \%$ & $100 \%$ \\
Seeds information & 57 & 65 & 116 & 170 & 52 & 460 \\
& $12.39 \%$ & $14.13 \%$ & $25.21 \%$ & 36.95 & $11.30 \%$ & $100 \%$ \\
Diseases and pest management & 45 & 65 & 110 & 155 & 85 & 460 \\
& $9.70 \%$ & $14.13 \%$ & $23.91 \%$ & $33.69 \%$ & $18.47 \%$ & $100 \%$ \\
Weather forecast & 25 & 75 & 180 & 190 & 45 & 460 \\
& $5.43 \%$ & $16.30 \%$ & $39.13 \%)$ & $41.30 \%$ & $9.78 \%$ & $100 \%$ \\
Fertilizer information & 15 & 85 & 125 & 135 & 45 & 460 \\
& $3.26 \%$ & $18.47 \%$ & $27.13 \%$ & $29.34 \%$ & $9.78 \%$ & $100 \%$ \\
Water availability & 35 & 65 & 140 & 175 & 45 & 460 \\
Farmers incentive packages & $7.60 \%$ & $14.13 \%$ & $30.43 \%$ & $38.04 \%$ & $9.78 \%$ & $100 \%$ \\
Irrigation & 20 & 65 & 155 & 165 & 55 & 460 \\
& $4.34 \%$ & $14.13 \%$ & $33.69 \%$ & $35.86 \%$ & $11.95 \%$ & $100 \%$ \\
Harvesting & 15 & 85 & 160 & 135 & 65 & 460 \\
Market information & $3.26 \%$ & $18.47 \%$ & $34.78 \%$ & $29.34 \%$ & $14.13 \%$ & $100 \%$ \\
Crop storage & 25 & 85 & 135 & 145 & 70 & 460 \\
\hline
\end{tabular}

Farmer's agricultural information requirements were also analyzed in the study as shown in Table 2 and demonstrated as figure 4. $190(41.30 \%)$ shown their interest in weather forecast, 175 (38.04\%) for water availability, 170 (36.95\%) were interested to get seeds quality and price information, $165(35.86 \%)$ farmers were interested in incentive packages, $155(33.69 \%)$ shown interest in diseases and pest management, $150(32.60 \%)$ farmers were interested in advanced cultivation systems 135 (29.34\%) acknowledged that they need fertilizer information For harvesting and posting harvesting information 145 (31.52\%) farmers were interested, To get market information regarding crop prices 120 (26.08) farmers shown their interest while for crops storage information $121(26.30 \%)$ were interested. 


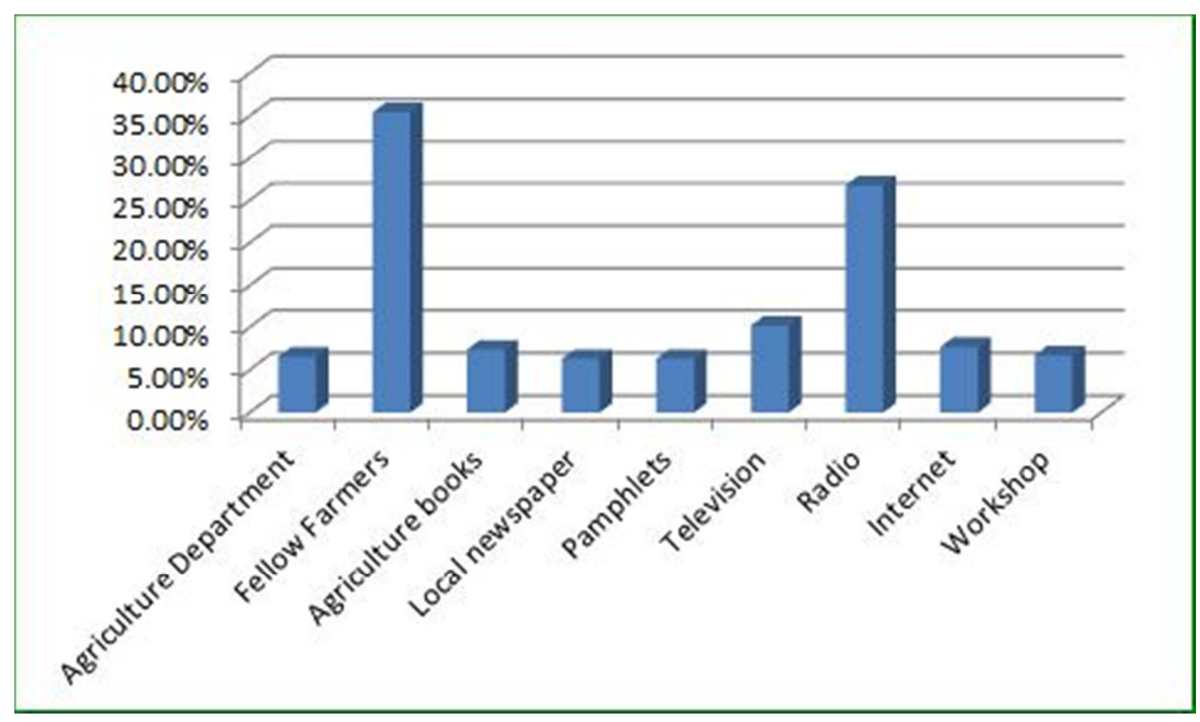

Figure 5. Sources of information used by farmers.

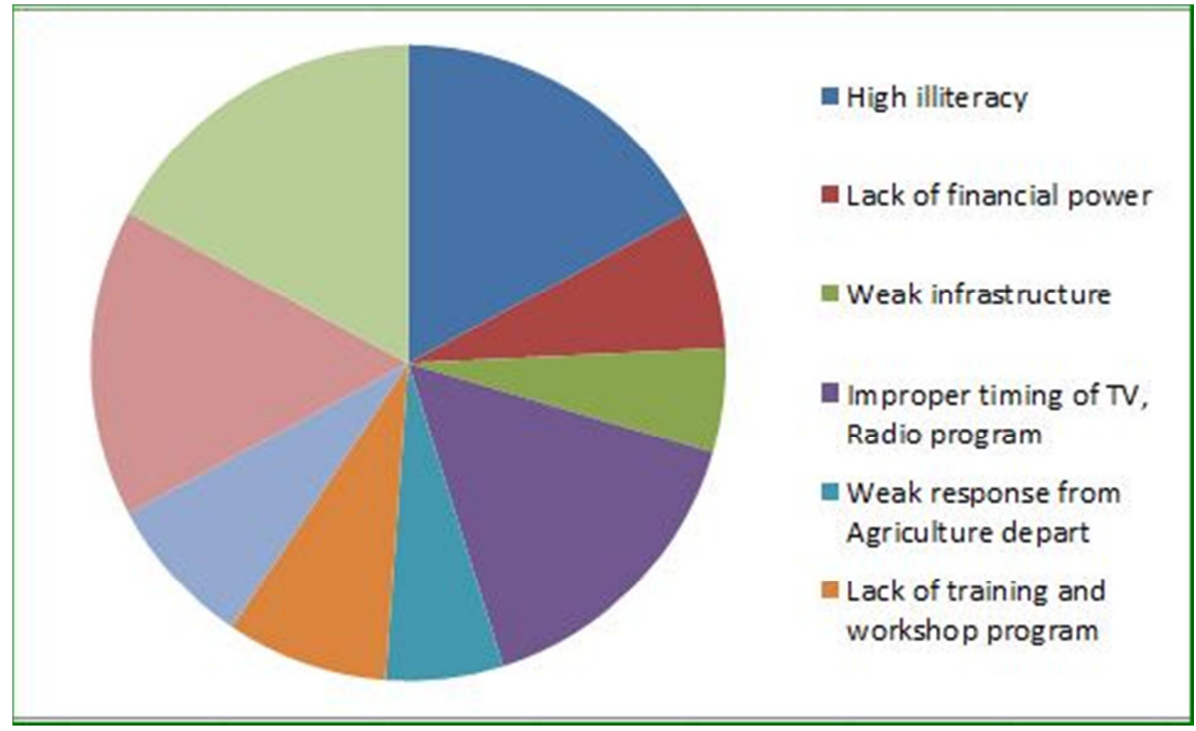

Figure 6. Barriers to access information.

Table 3. Sources of information used by the farmers.

\begin{tabular}{lllllll}
\hline Sources of Information & Never & Rarely & Occasional & Often & Very Often & Total \\
\hline \multirow{2}{*}{ Agriculture Department } & 180 & 190 & 55 & 30 & 5 & 460 \\
& $39.13 \%$ & $41.30 \%$ & $11.95 \%$ & $6.52 \%$ & $1.08 \%$ & $100 \%$ \\
Fellow Farmers & 20 & 30 & 75 & 163 & 172 & 460 \\
& $4.34 \%$ & $6.52 \%$ & $16.30 \%$ & $35.43 \%$ & $37.39 \%$ & $100 \%$ \\
Agriculture books & 176 & 186 & 42 & 34 & 22 & 460 \\
& $38.26 \%$ & $40.43 \%$ & $9.13 \%$ & $7.39 \%$ & $4.78 \%$ & $100 \%$ \\
Local newspaper & 120 & 165 & 121 & 29 & 25 & 460 \\
& $26.08 \%$ & $35.86 \%$ & $26.30 \%$ & $6.30 \%$ & $5.43 \%$ & $100 \%$ \\
Pamphlets & 110 & 145 & 123 & 47 & 35 & 460 \\
Television & $23.91 \%$ & $31.52 \%$ & $26.73 \%$ & $10.21 \%$ & $7.60 \%$ & $100 \%$ \\
& 45 & 132 & 164 & 65 & 54 & 460 \\
Radio & $9.78 \%$ & $28.69 \%$ & $35.65 \%$ & $14.13 \%$ & $11.73 \%$ & $100 \%$ \\
& 32 & 62 & 109 & 123 & 134 & 460 \\
Internet & $6.95 \%$ & $13.47 \%$ & $23.69 \%$ & $26.73 \%$ & $29.13 \%$ & $100 \%$ \\
\multirow{2}{*}{ Workshop } & 125 & 139 & 136 & 35 & 25 & 460 \\
& $4.34 \%$ & $14.13 \%$ & $33.69 \%$ & $7.69 \%$ & $11.95 \%$ & $100 \%$ \\
\hline
\end{tabular}

Farmers are using different sources to get agricultural information as shown in Table 3 and illustrated as figure 5. 
Majority of the farmers $172(37.39 \%)$ are getting information from their fellow famers followed by information through radio $134(29.13 \%), 65(14.0 \%)$, used Television as information source, $47(10.21 \%)$ farmers used pamphlets to get agricultural information, 35 (7.69\%) depend on internet to get information, $34(7.39 \%)$ farmers used agricultural books to get information, $31(6.73 \%)$ farmers available workshop source to get help, $30(6.52 \%)$ farmers approached agriculture depart to access information.

Table 4. Barriers faced by farmers to access information.

\begin{tabular}{|c|c|c|c|c|c|}
\hline Limitations & Significant & Highly significant & Least significant & No significant & Total \\
\hline \multirow{2}{*}{ High illiteracy } & 125 & 181 & 80 & 74 & 460 \\
\hline & $27.13 \%$ & $39.43 \%$ & $17.39 \%$ & $16.08 \%$ & $100 \%$ \\
\hline \multirow{2}{*}{ Lack of financial power } & 135 & 75 & 195 & 55 & 460 \\
\hline & $29.34 \%$ & $42.39 \%$ & $16.30 \%$ & $11.96 \%$ & $100 \%$ \\
\hline \multirow{2}{*}{ Weak infrastructure } & 75 & 56 & 38.26 & 153 & 460 \\
\hline & $16.30 \%$ & $12.17 \%$ & $16.30 \%$ & $33.26 \%$ & $100 \%$ \\
\hline Improper timing of $\mathrm{TV}$, Radio program & 145 & 165 & 77 & 73 & 460 \\
\hline \multirow{2}{*}{ Weak response from Agriculture depart } & 129 & 63 & 185 & 42 & 460 \\
\hline & $28.04 \%$ & $13.69 \%$ & $40.20 \%$ & $9.13 \%$ & $100 \%$ \\
\hline \multirow{2}{*}{ Lack of training and workshop program } & 118 & 87 & 179 & 76 & 460 \\
\hline & $25.65 \%$ & $18.91 \%$ & $38.91 \%$ & $16.52 \%$ & $100 \%$ \\
\hline \multirow{2}{*}{ Unawareness } & 77 & 82 & 143 & 158 & 460 \\
\hline & $16.73 \%$ & $17.82 \%$ & $31.08 \%$ & $34.34 \%$ & $100 \%$ \\
\hline Unavailability of local information center. & 143 & 166 & 81 & 70 & 460 \\
\hline \multirow{2}{*}{ Language problem } & 122 & 181 & 85 & 72 & 460 \\
\hline & $26.52 \%$ & $39.34 \%$ & $18.47 \%$ & $15.06 \%$ & $100 \%$ \\
\hline
\end{tabular}

Farmers are facing numerous problems while accessing information as shown in Table 4: and illustrated as figure 6. High illiteracy 181 (39.43\%), Lack of financial power 195 (42.39\%), Unavailability of local information center 166 (36.08\%) and language $122(26.52 \%)$ are highly significant problems faced by the rural farmers. Improper timing of TV and Radio program have also highly significant 165 (35.86\%).

\section{Conclusion}

In Pakistan Agriculture is the major source of income approximately fifty percent people is directly or indirectly involved in agriculture. In our country, farmers are facing a lot of problems like a lake of resources, inadequate agricultural information, lack of technology and awareness due to which agricultural production is getting down and negative growth is being observed every year. Keeping in view this disheartens situation first we analyzed the basic problems faced by the farmers, their need for agricultural information, the ease of availability/affordability and proposed a solution to meet their requirements. A platform has been developed where farmers and agriculture experts and other stakeholders can interact with each other to make strong collaboration and extend support to farmers to uplift the declining growth of agriculture in Pakistan.

\section{Future Impact of Research}

To overcome the communication gap between farmers and agricultural information providers in Pakistan this system can play a much better role. Through the use of our proposed framework farmers will be able to get the latest and important agricultural information on their mobile phones which increase their productivity and their livelihood will also be improved. The proposed framework is capable to meet all the essential requirements of farmers.

Our framework is not only helpful for the farmers but it can also extend support to other stakeholders like agriculture product sellers to shift from paper marketing for which they spend millions of Rupee to online marketing with no cost. The use of Information and Communication Technology (ICT) in the transfer of agricultural information is entirely an emerging field in Pakistan and has the potential to increase agricultural production.

\section{References}

[1] Pakistan Economic Survey 2015-16. Finance Division, Government of Pakistan.

[2] Aldosari, Fahad, et al. "Farmers' perceptions regarding the use of Information and Communication Technology (ICT) in Khyber Pakhtunkhwa-Northern Pakistan." Journal of the Saudi Society of Agricultural Sciences (2017).

[3] Jallo, Courtney. "Assessment of Information and Communication Technologies in Pakistan Agricultural Extension." 2016.

[4] Ngowi, E. E., A. S. Mwakalobo, and D. G. Mwamfupe. "Understanding the development of rural-ICT service providers in the Tanzanian agro-pastoral system." Livest Res Rural Dev 28.4 (2016): 2016.

[5] Muhammad, Sh, TE Lodhi, and GH A. Khan. "Farmers "Awareness of Agri. Radio and TV broadcasts and their preferences for different formats in the Punjab, Pakistan" Bulgarian Journal of Agricultural Science 22.3 (2016): 513516. 
[6] Armstrong, L., and D. Diepeveen. "Developing an information-driven ICT framework for Agriculture." (2008).

[7] Khan, Ghazanfar Ali, et al. "Present status and future preferences of electronic media as agricultural information sources by the farmers." Pak. J. Agri. Sci 47.2 (2010): 166172.

[8] Irfan, Muhammad, et al. "Role of mass media in the dissemination of agricultural technologies among farmers." International Journal of Agriculture and Biology (Pakistan) (2006).

[9] Rehman, F., et al. "Effect of farmers'sociao economic characteristic on access to agricultural information: Empirical evidence from Pakistan." Young (Up to 35) 52 (2013): 21-67.

[10] Ahmad, Mansoor, et al. "Interaction of extension worker with farmers and role of radio and television as sources of information in technology transfer: a case study of four villages of district Peshawar and Charsadda." Sarhad Journal of Agriculture 23.2 (2007): 515.

[11] Chattopadhyay, N. "Combating Effect of Climate Change and Climatic Variability on Indian Agriculture through Smart Weather Forecasting and ICT Application." Agriculture under Climate Change: Threats, Strategies and Policies 1 (2017).

[12] Ahmad, W., Noor, M. A., Afzal, I., Bakhtavar, M. A., Nawaz, M. M., Sun, X., Zhou, B., Ma, 2016.

[13] M., Zhao, M., 2016. Improvement of Sorghum Crop through Exogenous Application of Natural Growth-Promoting Substances under a Changing Climate. Sustainability. 8, 1330.

[14] Eitzinger, Anton, et al. "Geo Farmer: A monitoring and feedback system for agricultural development projects." Computers and Electronics in Agriculture 158 (2019): 109121. Mark Bell, Babar Shahbaz. "Agricultural extension in pakistan finding and proposed next steps". AIP working paper. March. 2016.

[15] Butt, Tahir Munir, et al. "Mode of ICTs applications in plant production and protection technology in rural PunjabPakistan." Transylvanian Review 13 (2017).

[16] Elly, Tumsifu \& Silayo, Ephraem Epafra (2013). Agricultural information needs and sources of the rural farmers in Tanzania. Library Review, 62 (8/9), 547-566.

[17] Bachhav, Nitin Bhagachand (2012). Information Needs of the Rural Farmers: A Study from Maharashtra, India: A Survey. Library Philosophy and Practice (e-journal). p. 1-12.

[18] Tologbonse, D., Fashola, O. \& Obadiah, M. (2008). Policy Issues in Meeting Rice Farmers Agricultural Information Needs in Niger State. Journal of Agricultural Extension, 1 (2), 84-94.

[19] Meitei, L. S. \& Devi, T. P. (2009). Farmers' information needs in rural Manipur: An assessment. Annals of library and information studies, 56 (1), 35-40.

[20] Elizabeth, Sabo (2007). Agricultural information needs of women farmers in Mubi region, Adamawa State. Journal of Tropical Agriculture, 45 (1-2), 69-71.

[21] Hossin, Arman \& Islam, Shariful (2012). Information Needs of Rural Women: A study of Three Villages of Bangladesh. Library Philosophy and Practice, 2012.

[22] Achigbue, Edwin. I. \& Anie, Sylvester. O. (2011). ICTs and Information Needs of Rural Female Farmers in Delta State, Nigeria. Library Philosophy and Practice, 2011.

[23] Mwakaje, A. G. (2010). Information communication technology for rural farmers'market access in Tanzania. Journal of Information Technology Impact, 10 (2), 111-128.

[24] Lwoga, E. T., Stilwell, C. and Ngulube, P. (2011). Access and use of agricultural information and knowledge in Tanzania. Library Review, 60 (5), 383-395.

[25] Wawire, Amos W., Sabina M. Wangia, and Julius J. Okello. "Determinants of Use of Information and Communication Technologies in Agriculture: The Case of Kenya Agricultural Commodity Exchange in Bungoma County, Kenya." Journal of Agricultural Science 9.3 (2017): 128.

[26] Khazaeli, Mostafa, Hiva Hanifi, Hamid Khazaeil, and Zahra Hanifi. "Survey the Role of Information Technology in Agricultural Development and Rural Womens Entrepreneurship." Global Journal of Management And Business Research (2018).

[27] Amin, S. B., \& Rahman, S. (2019). The Role of ICT in Energy Sector: Towards a Digital Bangladesh by 2021. In Energy Resources in Bangladesh (pp. 31-35). Springer, Cham.

[28] Lwoga, Edda Tandi, and Raphael Zozimus Sangeda. "ICTs and development in developing countries: A systematic review of reviews." The Electronic Journal of Information Systems in Developing Countries 85.1 (2019): e12060.

[29] Nnadi, O. I., Nwokolo, C. I., Enwelu, I. A. and Nnadi, U. V., 2019. An Assessment of Availability and Benefits of Information and Communication Technologies (ICTS) in Agricultural Development in Enugu State, Nigeria.

[30] Syed Sajidin hussian "Use of Information and Communication Technology (ICT) for enhancing efficiency in agriculture ", July 2016 .

[31] Trilles, Sergio, Joaquín Torres-Sospedra, Óscar Belmonte, F. Javier Zarazaga-Soria, Alberto González-Pérez, and Joaquín Huerta. "Development of an open sensorized platform in a smart agriculture context: A vineyard support system for monitoring mildew disease." Sustainable Computing: Informatics and Systems (2019). 